\title{
Pain Treatment of Newborns: Paracetamol Rectal Versus Intravenous Administration, A Randomised Open Clinical Trial
}

\author{
Laarman $\mathrm{ARC}^{1 *}$, Ris $\mathrm{JM}^{2}$, den Burger $\mathrm{JCG}^{2}$, Veldkamp $\mathrm{Al}^{2}$, Swart $\mathrm{EL}^{2}$, and van Weissenbruch $\mathrm{MM}^{1}$
}

${ }^{1}$ Neonatology Intensive Care Unit, VU University Medical Center Amsterdam. The Netherlands

${ }^{2}$ Clinical Pharmacology and Pharmacy, VU University Medical Center Amsterdam, The Netherlands

\begin{abstract}
Background and aim: Early recognition and treatment of pain is of great importance in the neonatal period. Paracetamol is the most frequent prescribed medicine for pain treatment. Administration of rectal paracetamol has limitations and the effectiveness can be variable in neonates. This study is based on the hypothesis that intravenous (iv) paracetamol is well tolerated, less variable and therefore more reliable in preterm neonates compared to rectal paracetamol. We therefore compared the effectiveness of intravenous and rectal administration in (preterm) neonates during a period of sickness accompanied by pain.
\end{abstract}

Methods: We included 21 neonates with pain, post menstrual age (PMA) of 28-44 weeks. They received paracetamol rectal or intravenous according to Dutch guidelines. Serum concentrations at steady state $(t=0,0.5,1,2,4,6$ hours) were determined.

Results: Clearance was dependent of weight, not of PMA. Estimated mean serum concentrations after four administrations were 4,8 $\pm 0,7,8,1 \pm 1,9$ and $10,2 \pm 3,1 \mathrm{mg} / \mathrm{L}$ and after rectal administration $4,1(\mathrm{n}=1), 12,6 \pm 6,0$ and $14,0 \pm 6,7 \mathrm{mg} / \mathrm{L}$. Hepato- or renal dysfunction were not observed.

Conclusion: Rectal and intravenous administration of paracetamol is well tolerated in (preterm) neonates. Rectal administration gives no paracetamol absorption or a major variation with inter- and intra-individual variation, which turns out to be unreliable especially in (pre)term neonates. Dosing of paracetamol (rectal and iv) should be based on weight instead of PMA. Further research is needed to define the exact dosing regime and target concentration of intravenous paracetamol in (preterm) neonates in comparison to the pain experience especially in preterm neonates.

Keywords: Neonatology; Pain; Paracetamol; Pharmacology

Abbreviations: Cl: Clearance; Cl/F: Apparent Clearance, L/Hour; CYP: Cytochrome P450 Dependent Enzymes; F: Bioavailability; Iv: Intravenous; Ka/F: Absorption Rate, L/Hour; METC: Medical Ethics Commission; NEC: Necrotising Enterocolitis; NICU: Neonatal Intensive Care Unit; PD: Pharmacodynamics; PK: Pharmacokinetics; PMA: Post Menstrual Age; V: Distribution; V/F: Apparent Volume Of Distribution, I

\section{Introduction}

Early recognition and treatment of pain is of great importance in the neonatal period. Moreover, exposure to pain without effective treatment of pain in this period might influence not only early but also later development [1,2]. Paracetamol is the most frequent prescribed medicine for pain treatment excluding neonates. In the neonatal intensive care unit (NICU) neonates are frequently exposed to painful procedures but most medication used for pain are opioids (morphine and fentanyl). These opioids can have severe adverse effects in premature neonates (depression of breathing, hypotension, urine retention) [3]. On the other hand a clear description of the exposure of rectal paracetamol in preterm and term neonates is lacking $[4,5]$. In addition, the administration, of rectal paracetamol has limitations such as administration problems, loss of paracetamol suppository with defecation and immaturity of the porta-rectal system especially in preterms leading to a variable absorption. Moreover, in some clinical conditions rectal administration of paracetamol is contraindicated such as necrotising enterocolitis (NEC) and severe thrombocytopenia $\left(<50 \times 10^{9} / 1\right)$.

Taken the adverse effects of opioids and limitations of rectal administration of paracetamol into account it is important to realize that (preterm) newborns has to be treated with medication characterized by good analgesic but less adverse effects or limitations in administration such as intravenous paracetamol. Currently rectal paracetamol is being used in preterm and terme neonates. We know that the effectiveness of rectal paracetamol can be variable in neonates $[6,7]$. Intravenous paracetamol being used in (preterm) neonates is not common. Improved understanding of the pharmacokinetics (PK) and pharmacodynamics (PD) of paracetamol will contribute to a safer, more effective and predictive analgesic dosing regimen for premature and term neonates. We think it is essential to estimate the effectiveness of intravenous paracetamol compared to rectal paracetamol, based on the hypothesis that intravenous paracetamol is well tolerated, less variable and therefore more reliable in preterm neonates compared to rectal paracetamol.

In the present study we used the paracetamol dosing regimen for optimal dosing exposure according to the Dutch guidelines and the described literature [8-10] The rectal and intravenous (iv) dosing is based on the post menstrual age (PMA) and weight in (preterm) neonates during a period of pain.

*Corresponding author: Drs. Laarman ARC, Neonatology Intensive Care Unit VU University Medical Center, De Boelelaan 1117, 1081 HV Amsterdam, The Netherlands, Tel: +31204442413; E-mail: arc.laarman@vumc.nl

Received March 05, 2015; Accepted March 30, 2015; Published April 06, 2015

Citation: Laarman ARC, Ris JM, den Burger JCG, Veldkamp Al, Swart EL, et al. (2015) Pain Treatment of Newborns: Paracetamol Rectal Versus Intravenous Administration, A Randomised Open Clinical Trial. J Neonatal Biol 4: 172 doi:10.4172/2167-0897.1000172

Copyright: @ 2015 Laarman ARC, et al. This is an open-access article distributed under the terms of the Creative Commons Attribution License, which permits unrestricted use, distribution, and reproduction in any medium, provided the original author and source are credited. 


\section{Methods}

\section{Study registration and ethics}

This study was an open randomised clinical single center trial. The primary outcome was the $\mathrm{PK}$ of iv and rectal paracetamol administration in term and premature neonates. The secondary outcome was the PD (pain) and safety (hepatic and renal tolerance) of iv and rectal paracetamol administration in term and premature neonates. Twenty-four neonates were included following study registration, approval by the medical ethics commission (METC VU Medical Center, Amsterdam) and written parental informed consent.

Contra-indications for inclusion were, the absence of an arterial access (blood sampling for PK), renal- and/or hepatocellular dysfunction and severe thrombocytopenia $\left(<50 \times 10^{9} / 1\right)$, necrotising enterocolitis and rectal blood loss.

\section{Clinical characteristics, medication, dosing regimen and} blood sample strategy

Twenty-four neonates either preterm (28-37 weeks gestational age) or term (37-44 weeks gestational age) were included. Pain scores were collected by the Comfort NEO score (Dutch validated pain score system). Neonates with pain (Comfort NEO score $>14$ ) received paracetamol iv or rectal after randomisation according to Dutch guidelines independent of the cause of pain (medical, postoperative, hematoma). Rectal dosing (28-31 weeks) loading dose $20 \mathrm{mg} / \mathrm{kg}$ followed by $20 \mathrm{mg} / \mathrm{kg}$ every 12 hour, (32-35 weeks) loading dose 30 $\mathrm{mg} / \mathrm{kg}$ followed by $20 \mathrm{mg} / \mathrm{kg}$ every 12 hour and (36-44 weeks) loading dose $30 \mathrm{mg} / \mathrm{kg}$ followed by $20 \mathrm{mg} / \mathrm{kg}$ every 8 hour. Intravenous dosing (28-31 weeks) loading dose $20 \mathrm{mg} / \mathrm{kg}$ followed by $10 \mathrm{mg} / \mathrm{kg}$ every 12 hour, (32-35 weeks) loading dose $20 \mathrm{mg} / \mathrm{kg}$ followed by $10 \mathrm{mg} / \mathrm{kg}$ every 8 hour and (36-44 weeks) loading dose $20 \mathrm{mg} / \mathrm{kg}$ followed by $10 \mathrm{mg} /$ kg every 6 hour.

The prescribed dose of intravenous paracetamol $10 \mathrm{mg} / \mathrm{ml}$ (Perfalgan $^{\odot}$, Bristol-Myers Squibb) was administrated undiluted in 15 minutes. Paracetamol suppositories of $30 \mathrm{mg}$ (UMC stRadboud, Pharmacy, Nijmegen, The Netherlands) and $60 \mathrm{mg}$ (Centrafarm B.V, Etten-Leur, the Netherlands) were used to achieve the desired paracetamol dose. The suppository of $30 \mathrm{mg}$ was fabricated for this study in a triglyceride base in gelatin capsules. Only complete suppositories were administrated. The correct handling was done by the nurse. Blood samples were taken through the arterial route at steady state around the fifth administration of paracetamol, samples were taken at $\mathrm{t}=0,0.5,1$, $2,4,6$ hour. These time points include the $\mathrm{C}_{\text {through }}$ and $\mathrm{C}_{\max }$ of neonates after administration of paracetamol either intravenous (15 minutes after infusion) or rectal paracetamol (1,5-5 hours).

Safety data are limited for paracetamol in neonates. It is difficult to predict acute liver or kidney injury in neonates. Renal and hepatocellular function has been measured with serum creatinine and alanine and aspartate aminotransferase. Thrombocyte count were measured by taken blood samples before randomisation and after the fifth administration of paracetamol.

\section{Blood samples analysis}

Plasma paracetamol samples were analysed by using a validated liquid chromatography tandem mass spectrometric (LC-MS/MS) (unpublished data on file, M Ris, ARC Laarman, JCG den Burger, DJAR Moes, AI Veldkamp, EL Swart, MM van Weissenbruch. Pharmacokinetic analysis of paracetamol after rectal or intravenous administration in neonates. VU Medical Center Amsterdam, The Netherlands) [11]. Linearity was established between $0,94 \mathrm{mg} / \mathrm{L}$ and $49,6 \mathrm{mg} / \mathrm{L}$. The lower limit of quantification was $0,94 \mathrm{mg} / \mathrm{L}$ and variation coefficients of inter- and intra assay accuracy and precision were below $15 \%$.

\section{Exposure to paracetamol}

Previous research has led to the development of two separate pharmacokinetic models in NONMEM (V6.2.0 Icon Development Solutions, Ellicott City, MD, USA) [12,13]. Intravenous administration was described best with a one compartmental pharmacokinetic model with first-order elimination. Random effect parameters for interindividual variability were identified on clearance $(\mathrm{Cl})$ and volume of distribution $(\mathrm{V})$. Weight was the only identified covariate and described $54,9 \%$ of variance. The data after rectal administration were described best with a two compartmental pharmacokinetic model with first order elimination. Random effect parameters for inter-individual variability were identified on $\mathrm{Cl} / \mathrm{F}$ (apparent clearance, 1/hour), V/F (apparent volume of distribution, $\mathrm{l}$ ) and $\mathrm{K}_{\mathrm{a}} / \mathrm{F}$ (absorption rate $\mathrm{l} /$ hour) and not on $\mathrm{F}$ (bioavailability). Also here weight was the only identified covariate. Bioavailability (F) was fixed on 0,6 for achieving the same clearance as with intravenous administration [5]. In both models post menstrual age (PMA) did not significant predict inter-individual variance (unpublished data on file, M Ris, ARC Laarman, JCG den Burger, DJAR Moes, AI Veldkamp, EL Swart, MM van Weissenbruch. Pharmacokinetic analysis of paracetamol after rectal or intravenous administration in neonates. VU Medical Center Amsterdam, The Netherlands) [11]. With the developed pharmacokinetic models the individual clearance of paracetamol of each participant of the study was determined.

Exposure to paracetamol was calculated using the formula: Exposure $=$ Dose $^{\star} \mathrm{F} / \mathrm{Cl}$ and presented as average serum concentration $\left(\mathrm{mg}^{\star} \mathrm{h} / \mathrm{L}\right)$. If patients were excluded for PK-analysis the exposure was calculated of all the concentration-time points using the trapezoidal rule between the sampled time period $(\mathrm{t}=0$ till $\mathrm{t}=6)$.

\section{Statistics}

Clinical characteristics were reported by mean, range and incidence. The differences between intravenous and rectal paracetamol dosing regimen, effect, exposure and serum concentrations were analysed with the Mann Whitney U test. A p-value $<0,05$ was significant.

\section{Results}

Twenty-four neonates participated in the trial. Nine neonates have received iv paracetamol and fifteen neonates have received rectal paracetamol. The clinical characteristics and the indication for pain treatment in these 24 neonates are reported in Tables 1 and 2. Three neonates were excluded for analyses due to rectal administration problems and/or no absorption of paracetamol. There was no elevation of serum creatinine and alanine and aspartate aminotransferase. In all the patients the clearance of paracetamol was dependent on the actual weight during treatment instead of the regularly used PMA (Figure 1).

\section{Paracetamol intravenous}

In literature a target serum paracetamol concentration of $>10$ $m g^{\star} h / 1$ is described [14]. After four consecutive iv dosages the estimated serum concentrations (mean $\pm \mathrm{SD}$ ) of paracetamol were 4,8 \pm 0,7 mg^h/l (PMA 28-31 weeks), 8,1 $\pm 1,9$ mg^h/l (PMA 32-35 weeks) and 10,2 $\pm 3,1 \mathrm{mg}^{\star} \mathrm{h} / \mathrm{l}$ (PMA 36-44 weeks). 
Pge 3 of 5

\begin{tabular}{|c|c|c|c|c|c|c|}
\hline Patient characteristics & $\begin{array}{c}\text { PMA 28-31 weeks } \\
*_{1}\end{array}$ & $\begin{array}{c}\text { PMA 28-31 weeks } \\
*_{1}^{* 1}\end{array}$ & $\begin{array}{c}\text { PMA } 32-35 \text { weeks } \\
*_{2}\end{array}$ & $\begin{array}{c}\text { PMA } 32-35 \text { weeks } \\
{ }^{* 2}\end{array}$ & $\begin{array}{c}\text { PMA } 36-44 \text { weeks } \\
*_{3}\end{array}$ & $\begin{array}{c}\text { PMA } 36-44 \text { weeks } \\
* 3\end{array}$ \\
\hline Group & iv & rectal & iv & rectal & iv & rectal \\
\hline $\mathrm{N}$ (total $=24$ ) & $3(3 \precsim)$ & $3(2 \AA)$ & $3(0$ ภ $)$ & $4(3 \overbrace{}^{\Uparrow})$ & $3(1 \overbrace{}^{-1})$ & $8(4$ ふ) \\
\hline $\begin{array}{c}\text { Mean PMA } \\
\text { (weeks + days) } \\
\text { (at start) }\end{array}$ & $\begin{array}{c}304 / 7 \\
(302 / 7-31 \text { 0/7) }\end{array}$ & $\begin{array}{c}294 / 7 \\
(286 / 7-306 / 7)\end{array}$ & $\begin{array}{c}323 / 7 \\
(323 / 7-324 / 7)\end{array}$ & $\begin{array}{c}343 / 7 \\
(32 \text { 2/7-35 3/7) }\end{array}$ & $\begin{array}{c}392 / 7 \\
(371 / 7-430 / 7)\end{array}$ & $\begin{array}{c}383 / 7 \\
(370 / 7-410 / 7)\end{array}$ \\
\hline $\begin{array}{l}\text { Mean age (days) } \\
\quad \text { (birth - start) }\end{array}$ & $3(1-6)$ & $11(1-28)$ & $4(2-7)$ & $2,5(1-4)$ & $8(1-22)$ & $4(1-12)$ \\
\hline $\begin{array}{l}\text { Mean weight } \\
\text { (gram) }\end{array}$ & $\begin{array}{c}1740 \\
(1535-1890)\end{array}$ & $\begin{array}{c}1225 \\
(1005-1485)\end{array}$ & $\begin{array}{c}1430 \\
(1030-1750)\end{array}$ & $\begin{array}{c}2395 \\
(1710-2717)\end{array}$ & $\begin{array}{c}3235 \\
(2450-4555)\end{array}$ & $\begin{array}{c}2845 \\
(2115-4090)\end{array}$ \\
\hline $\begin{array}{l}\text { Loading dose } \\
\text { (mg/kg/day) }\end{array}$ & $\begin{array}{c}20.5 \\
(20-21.5)\end{array}$ & $\begin{array}{c}24.5 \\
(20.2-29.8)\end{array}$ & $\begin{array}{c}19.7 \\
(19.4-30)\end{array}$ & $\begin{array}{c}31.4 \\
(24.4-35)\end{array}$ & $\begin{array}{c}20.1 \\
(19.8-20.4)\end{array}$ & $\begin{array}{c}28.9 \\
(24.5-34.2)\end{array}$ \\
\hline $\begin{array}{c}\text { Dose } \\
\text { (mg/kg/day) }\end{array}$ & $\begin{array}{c}20.7 \\
(20-22.2)\end{array}$ & $\begin{array}{c}49 \\
(40.4-59.7)\end{array}$ & $\begin{array}{c}29,6 \\
(29.1-30)\end{array}$ & $\begin{array}{c}50 \\
(44.1-70)\end{array}$ & $\begin{array}{c}40,1 \\
(39.5-40.8)\end{array}$ & $\begin{array}{c}69,9 \\
(49.7-85.1)\end{array}$ \\
\hline
\end{tabular}

Table 1: Patient characteristics and paracetamol loading dose intravenous and rectal in different patient groups: * 1: PMA 28-31 weeks, ${ }^{*}$ : PMA $32-35$ weeks, ${ }^{*} 3$ PMA 36-44 weeks.

\begin{tabular}{|c|c|c|c|c|c|}
\hline Male $=$ M & Weight & PMA & Rectal/ intravenous & Group & Reason Inclusion: \\
\hline Female $=$ F & gram & wk+day & & PMA & herne \\
\hline M & 2185 & $39+3$ & rectal & a terme & gastroschisis \\
\hline M & 2400 & $37+2$ & rectal & a terme & gastroschisis \\
\hline F & 2450 & $37+1$ & rectal & $28-31$ & pain other cause \\
\hline M & 3620 & $40+4$ & intravenous & jejunal atresia \\
\hline M & 1890 & $30+2$ & rectal & $32-36$ & esophageal atresia \\
\hline F & 2717 & $35+2$ & intravenous & esophageal atresia \\
\hline F & 1520 & $32+3$ & rectal & $31-36$ & gastroschisis \\
\hline F & 2115 & $37+6$ & intravenous & pain other cause \\
\hline M & 2700 & $37+1$ & rectal & $28-44$ & pain other cause \\
\hline F & 1185 & $29+0$ & duodenal web \\
\hline F & 1800 & $30+3$ & rectal & $32-31$ & pain other cause \\
\hline F & 2450 & $34+6$ & intravenous & duodenal atresia \\
\hline M & 1750 & $32+3$ & intravenous & $31-36$ & pain other cause \\
\hline M & 2450 & $37+4$ & intravenous & $28-31$ & pain other cause \\
\hline F & 1635 & $31+0$ & rectal & $32-36$ & esophageal atresia \\
\hline F & 1710 & $32+2$ & intravenous & $31-36$ & hernia diafragmatica \\
\hline M & 1030 & $32+4$ & rectal & $36-44$ & lung biopsy \\
\hline M & 3050 & $37+0$ & intravenous & $36-44$ & central venous catheter \\
\hline
\end{tabular}

Table 2: Patient characteristics.

\section{Paracetamol rectal}

The estimated serum concentrations (mean $\pm \mathrm{SD}$ ) of paracetamol after four consecutive rectal dosages were $4,1 \mathrm{mg}^{\star} \mathrm{h} / \mathrm{l}$ (PMA 28-31 weeks), 12,6 \pm 6,0 mg^h/l (PMA 32-35 weeks) and 14,0 $\pm 6,7 \mathrm{mg}^{\star} \mathrm{h} / \mathrm{l}$ (PMA 36-44 weeks).

After rectal administration of paracetamol there was either no absorption or a major variation especially in the neonates with a PMA of 28-31 and 32-35 weeks. There was a major variation within the estimated serum paracetamol concentrations in all neonates after rectal administration. Almost all neonates, except one neonate with a PMA of 36-44 weeks, had reached the target serum paracetamol concentration $>10 \mathrm{mg}$ h/l.

Two neonates with a PMA of 28-31 weeks were excluded for analyses due to rectal administration problems and/or no absorption of paracetamol. In addition, two neonates with a PMA of 36-44 weeks were excluded because of no increase but decline in serum paracetamol concentration compared to $\mathrm{t}=0$ without signs of rectal administration problems (Figure 2).

\section{Limitations of rectal paracetamol dosing versus iv paracetamol dosing}

All neonates received paracetamol iv or rectal according to Dutch guidelines and almost all patients received the prescribed iv paracetamol dose in contrast to the rectal paracetamol dose. The iv paracetamol can easily be administrated in the exact prescribed dose.

For the rectal paracetamol it was impossible to administrate paracetamol in the exact prescribed dose because of the limitation of the suppository of $30 \mathrm{mg}$. Due to this limitation the administrated rectal paracetamol dose was higher than the prescribed paracetamol dose, especially in neonates with a PMA of 28-31 and 32-35 weeks.

All serum paracetamol concentrations were corrected for the administrated iv and rectal paracetamol dose. After four consecutive iv dosages the corrected serum concentrations (mean \pm SD) of paracetamol were 4,7 $\pm 0,7 \mathrm{mg}^{\star} \mathrm{h} / \mathrm{l}$ (PMA 28-31 weeks), 8,3 $\pm 1,9$ mg^h/l (PMA 32-35 weeks) and 10,3 $\pm 3,3$ mg*h/l (PMA 36-44 weeks). The corrected serum concentrations (mean $\pm \mathrm{SD}$ ) of paracetamol after four consecutive rectal dosages were $3,2 \mathrm{mg}$ h/l (PMA 28-31 weeks), 


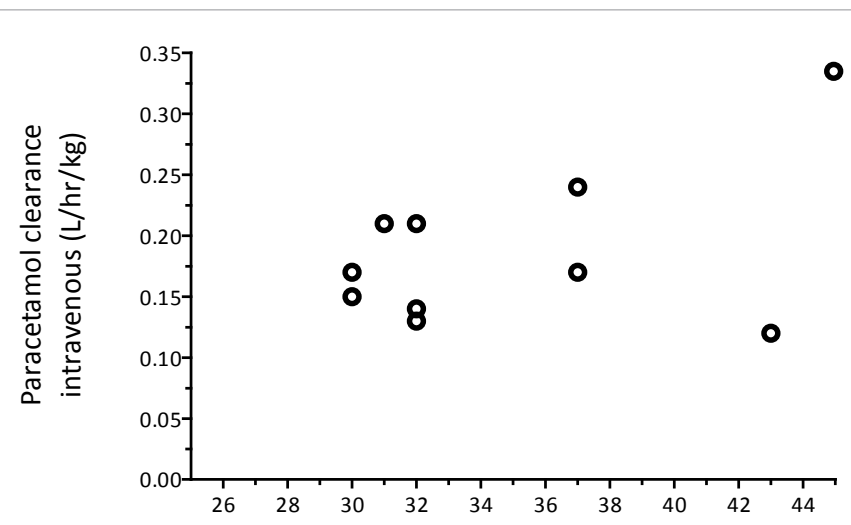

Post menstrual age (PMA) in weeks

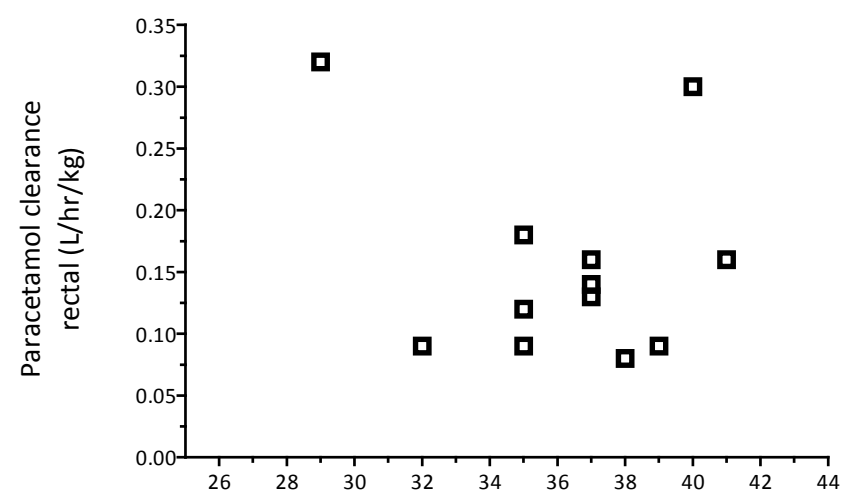

Post menstrual age (PMA) in weeks

Figure 1: Clearance of paracetamol (iv and rectal).

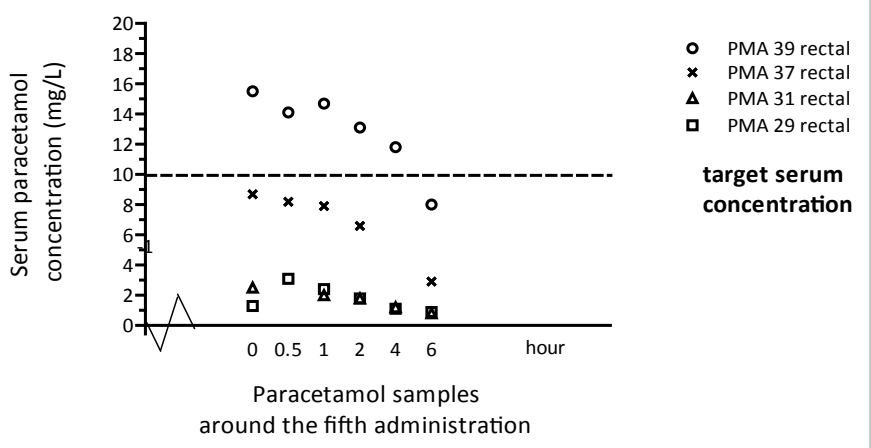

Figure 2: Excluded data due to rectal administration problems and/or no absorption of rectal paracetamol.

9,4 $\pm 2,9$ mg^h/l (PMA 32-35 weeks) and 11,4 $\pm 4,3$ mg*h/l (PMA 3644 weeks).

The serum paracetamol concentration of iv paracetamol didn't change after correction for the administrated dose. The serum paracetamol concentration of rectal paracetamol was less variable and with nearly no difference in mean serum concentration after correction for the administrated dose (Figure 3).

\section{Discussion}

We here report that the clearance of paracetamol rectal and intravenous was dependent of the neonatal weight during treatment instead of the regularly used PMA according to the current Dutch guidelines. Recent data from Allegaert et al. showed that variance in clearance of intravenous paracetamol is primarily explained by weight and suggests that dosing of intravenous paracetamol should be based on weight instead of PMA [15].

In our study the absorption of rectal paracetamol turns out to be very unreliable especially for the preterm neonates. Hansen et al. described a variable absorption of rectal paracetamol in neonates, with no clear description of paracetamol absorption in this population [4]. We observed either no absorption or a major variation in serum paracetamol concentration after rectal paracetamol administration in almost all neonates and especially in preterm neonates with a PMA of 28-31 weeks. In some patients studied, irrespective PMA, there were also problems with the route of rectal administration of paracetamol.

In general it is very difficult to administrate the rectal paracetamol in the exact prescribed dose because of the limitation of the suppository of $30 \mathrm{mg}$. Due to these limitations most of the neonates have received a higher rectal paracetamol dose than have been prescribed.

Therefore we have to be precautious with rectal paracetamol in both preterm and term neonates because rectal paracetamol might be very unreliable in these children. Tinner et al. described a possible increase of pain response, based on the neonatal pain and discomfort scale, in term and near term neonates who received rectal paracetamol soon after an assisted vaginal delivery [16].

We here showed that intravenous paracetamol administration is more accurate applicable in preterm and term neonates, with less variation in serum paracetamol concentration than rectal paracetamol administration. In almost all neonates the estimated serum paracetamol concentration was below the target serum concentration of $10 \mathrm{mg}^{\star} \mathrm{h} / \mathrm{l}$. Most of the neonates received co-medication such as opioids because
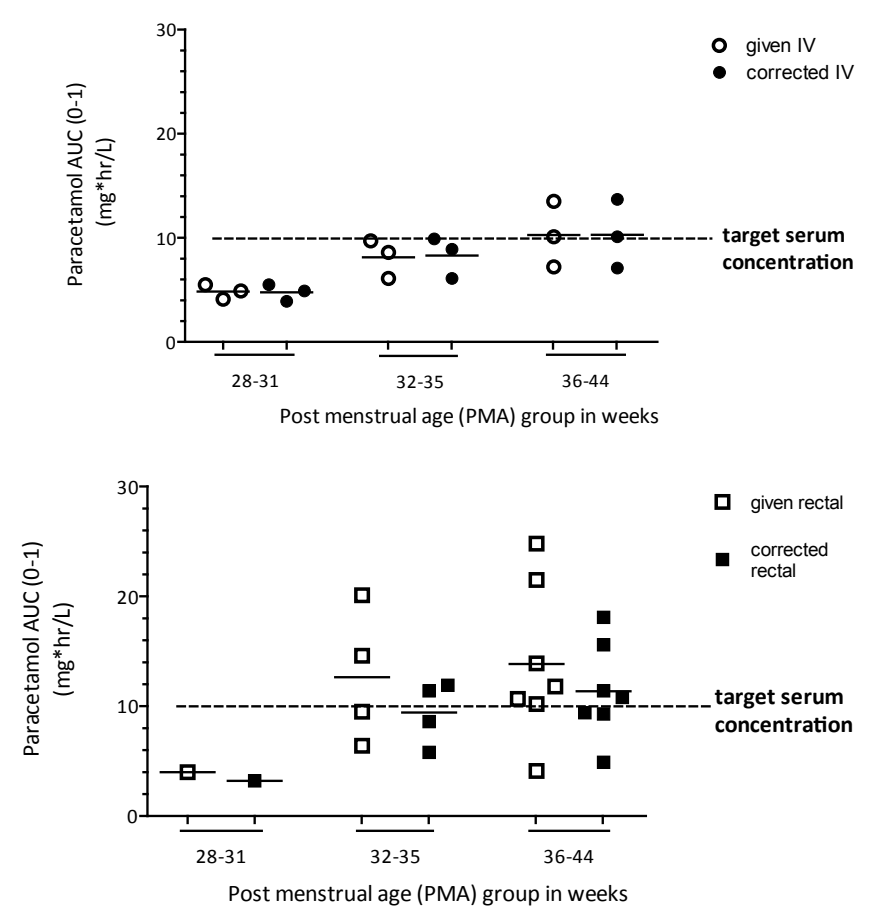

Figure 3: Corrected estimated mean Acetaminophen serum concentrations at dose 5 . 
of a surgical procedure, the iv or rectal paracetamol was added for pain treatment after the surgical procedure. Wong et al. described variable results in children who received perioperative paracetamol. Rectal paracetamol did not reduce the opioid requirements, but iv paracetamol reduced the opioid requirement in children aged 6-24 months [17].

So far it is not clear if the prescribed paracetamol dose is accurate enough for these neonates because of the low serum paracetamol concentrations. Otherwise the target serum paracetamol concentration of $10 \mathrm{mg}^{\star} \mathrm{h} / \mathrm{l}$ might not be appropriate for these neonates especially in preterms. The use of co-medication makes it difficult to investigate this in a proper way. Pain experience can be another factor in these preterm neonates. They might experience pain different compared to older neonates.

Recent study from James et al. [18] showed that alanine aminotransferase and acetamionophen concentrations are less sensitive in predicting the development of acute liver injury. In our study we measured serum alanine and aspartate aminotransferase before and during rectal and intravenous paracetamol. We have observed no elevation of alanine and aspartate aminotransferase. As a result it is difficult to make any prediction regarding acetaminophen induced liver injury.

We are aware that the current report and study design have limitations. It is a small single center study in which we included only twenty-four neonates. Some neonates were treated with co-medication (morphine or fentanyl) which makes it impossible to evaluate if the target serum paracetamol concentration of $>10 \mathrm{mg}^{*} \mathrm{~h} / \mathrm{l}$ is optimal for the neonates studied with regard to the pain experience. We didn't evaluated metabolites of paracetamol in both plasma and urine of the neonates. These metabolites are important in further understanding the pharmacokinetics (PK) of paracetamol $[19,20]$.

Based on these study results we are able to indicate inter- and intra-individual variation of absorption of paracetamol showing that the effectiveness of rectal paracetamol is unreliable in preterm and term neonates. Intravenous paracetamol administration, however, seems to be far more reliable, is well tolerated and more effective than rectal paracetamol administration in both preterm and term neonates. Further research is required to define pain experience especially in preterm neonates and for defining the dosing regime and target concentrations in using intravenous paracetamol in preterm and term neonates.

\section{Conclusion}

Rectal and intravenous administration of paracetamol is well tolerated in (preterm) neonates. Rectal administration gives no paracetamol absorption or a major variation with inter- and intraindividual variation, which turns out to be unreliable especially in (pre) term neonates. Dosing of paracetamol (rectal and iv) should be based on weight instead of PMA. Further research is needed to define the exact dosing regime and target concentration of intravenous paracetamol in (preterm) neonates in comparison to the pain experience especially in preterm neonates.

\section{Acknowledgments}

These data has been presented in ' $14^{\text {th }}$ European Society for Developmental Perinatal and Paediatric Congress (ESDPPP 2013).

We are supported by the Fund for Scientific Research (The Netherlands) by Fonds Nuts Ohra.

\section{References}

1. Grunau RE, Whitfield MF, Petrie-Thomas J, Synnes AR, Cepeda IL, et al (2009) Neonatal pain, parenting stress and interaction, in relation to cognitive and motor development at 8 and 18 months in preterm infants. Pain 143: 138146.

2. Grunau RE (2013) Neonatal pain in very preterm infants: long-term effects on brain, neurodevelopment and pain reactivity. Rambam Maimonides Med $\mathrm{J} 4$ : e0025.

3. Niesters M, Overdyk F, Smith T, Aarts L, Dahan A (2013) Opioid-induced respiratory depression in paediatrics: a review of case reports. $\mathrm{Br} \mathrm{J}$ Anaesth 110: $175-182$.

4. Hansen TG, O'Brien K, Morton NS, Rasmussen SN (1999) Plasma paracetamol concentrations and pharmacokinetics following rectal administration in neonates and young infants. Acta Anaesthesiol Scand 43: 855-859.

5. Anderson BJ, van Lingen RA, Hansen TG, Lin YC, Holford NH (2002) Acetaminophen developmental pharmacokinetics in premature neonates and infants: a pooled population analysis. Anesthesiology 96: 1336-1345.

6. van Lingen RA, Deinum JT, Quak JM, Kuizenga AJ, van Dam JG, et al. (1999) Pharmacokinetics and metabolism of rectally administered paracetamol in preterm neonates. Arch Dis Child Fetal Neonatal Ed 80: F59-63.

7. van Lingen RA, Deinum HT, Quak CM, Okken A, Tibboel D (1999) Multipledose pharmacokinetics of rectally administered acetaminophen in term infants. Clin Pharmacol Ther 66: 509-515.

8. Allegaert K, Anderson BJ, Naulaers G, de Hoon J, Verbesselt R, et al. (2004) Intravenous paracetamol (propacetamol) pharmacokinetics in term and preterm neonates. Eur J Clin Pharmacol 60: 191-197.

9. Allegaert K, Naulaers G, Vanhaesebrouck S, Anderson BJ (2013) The paracetamol concentration-effect relation in neonates. Paediatr Anaesth 23: 45-50.

10. Cuzzolin L, Antonucci R, Fanos V (2013) Paracetamol (acetaminophen) efficacy and safety in the newborn. Curr Drug Metab 14: 178-185.

11. Ris M, Laarman ARC, den Burger JCG, Moes DJAR, Veldkamp Al, et al. Pharmacokinetic analysis of paracetamol after rectal or intravenous administration in neonates. Unpublished data on file.

12. Lindbom L, Pihlgren P, Jonsson EN (2005) PsN-Toolkit--a collection of computer intensive statistical methods for non-linear mixed effect modeling using NONMEM. Comput Methods Programs Biomed 79: 241-257.

13. Keizer RJ, van Benten M, Beijnen JH, Schellens JH, Huitema AD (2011) Piraña and PCluster: a modeling environment and cluster infrastructure for NONMEM. Comput Methods Programs Biomed 101: 72-79.

14. Anderson BJ, Woollard GA, Holford NH (2001) Acetaminophen analgesia in children: placebo effect and pain resolution after tonsillectomy. Eur $\mathrm{J}$ Clin Pharmacol 57: 559-569.

15. Allegaert K, Palmer GM, Anderson BJ (2011) The pharmacokinetics of intravenous paracetamol in neonates: size matters most. Arch Dis Child 96: 575-580.

16. Tinner EM, Hoesli I, Jost K, Schöbi N, Ulrich Megged Y, et al. (2013) Rectal paracetamol in newborn infants after assisted vaginal delivery may increase pain response. J Pediatr 162: 62-66.

17. Wong I, St John-Green C, Walker SM (2013) Opioid-sparing effects of perioperative paracetamol and nonsteroidal anti-inflammatory drugs (NSAIDs) in children. Paediatr Anaesth 23: 475-495.

18. James LP, Gill P, Simpson P (2013) Predicting risk in patients with acetaminophen overdose. Expert Rev Gastroenterol Hepatol 7: 509-512.

19. Imti Choonara (2005) Drug Metabolism in the Neonate. J. Arab Neonatal Forum 2: 1-4

20. Schreuder MF, Bueters RR, Allegaert K (2014) The interplay between drugs and the kidney in premature neonates. Pediatr Nephrol 29: 2083-2091. 